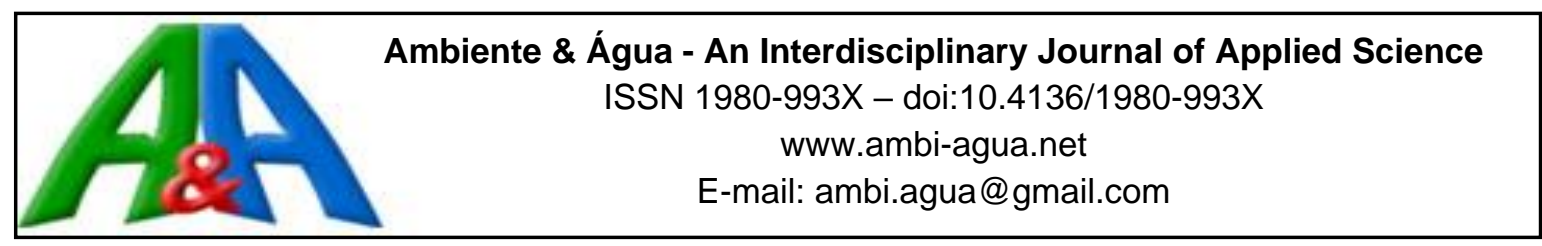

\title{
Atividade da malato desidrogenase muscular de Astyanax bimaculatus da bacia hidrográfica do rio Una como biomarcadora de impacto ambiental
}

\author{
doi:10.4136/ambi-agua.1898
}

Received: 28 Aug. 2016; Accepted: 17 Nov. 2016

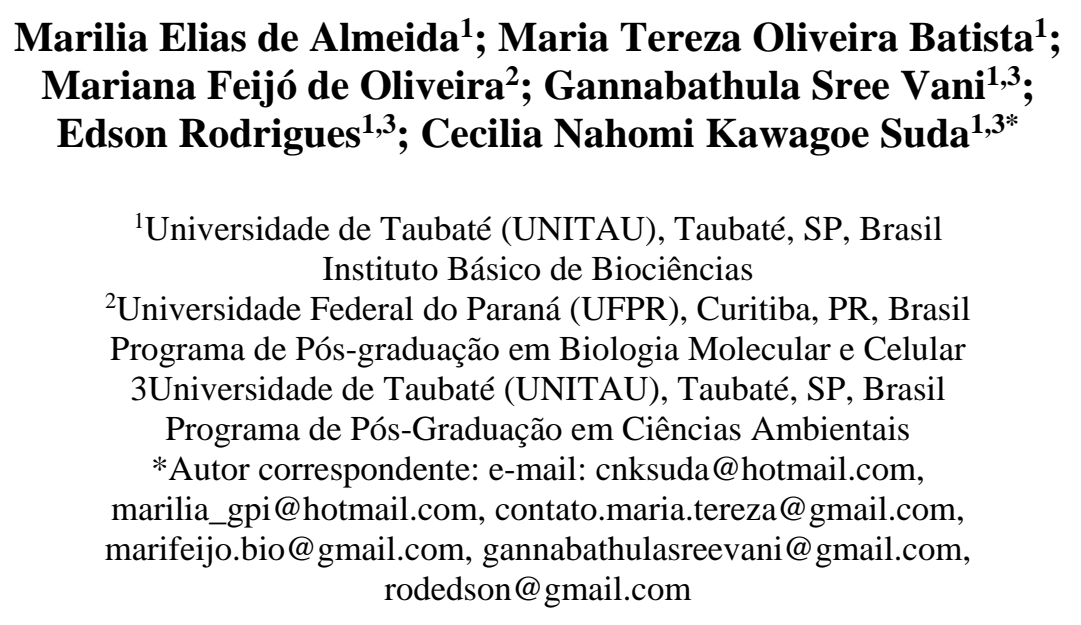

\section{RESUMO}

A atividade da enzima malato desidrogenase (MDH) e de suas isoformas podem variar em peixes, em função do ambiente em que vivem. O objetivo deste trabalho foi investigar a atividade de MDH no tecido muscular de Astyanax bimaculatus (lambari do rabo amarelo) proveniente de três pontos de coleta (P1, P2 e P3) na bacia hidrográfica do rio Una (Taubaté, SP) e avaliar o seu potencial como marcador bioquímico de alteração ambiental. As formas citosólica e mitocondrial da MDH foram extraídas dos músculos. Os resultados indicaram que a atividade total da enzima foi 1,8 e 2,5 vezes maior em A. bimaculatus do sítio P2, em relação aos espécimes coletados em P1 e P3, respectivamente. Foram detectadas 7 isoformas de MDH no tecido muscular (MDH-1 a MDH-7). Os níveis de MDH-1 de espécimes coletados em P3 foram 1,9 e 2,4 vezes maiores do que daqueles de P1 e P2, respectivamente. Entretanto, os níveis de MDH-5, -6 e -7, foram significativamente menores nos espécimes coletados em P3, em comparação com os de P1. Esses resultados têm, possivelmente, relação com a qualidade da água, considerando que P3 é o mais poluído dos três sítios de coleta. A atividade de MDH muscular de A. bimaculatus foi moduladada pelo ambiente. Portanto, pode se concluir que essa enzima possui potencial como marcador bioquímico de alteração ambiental em bacias da região neotropical, nas quais essa espécie ocorre.

Palavras-chave: enzimas, lambari do rabo amarelo, poluição da água. 


\title{
Muscle malate dehydrogenase activity of Astyanax bimaculatus from Una River Basin as a biomarker of environmental impact
}

\begin{abstract}
The enzymatic activity of malate dehydrogenase (MDH) and its isoforms may vary in fishes according their living environment. The aim of this work was to investigate the activity of MDH in the muscle tissue of Astyanax bimaculatus (locally called as lambari do rabo amarelo), collected at three different points (P1, P2 and P3) in the Una River Basin (Taubaté, $\mathrm{SP})$, to evaluate it as a candidate biomarker for environmental change. Cytosolic and mitochondrial isoforms of MDH were extracted from muscles. The results indicated that the total enzyme activity was 1.8 and 2.5 times higher in $A$. bimaculaus at $\mathrm{P} 2$, in comparison to specimens collected at P1 and P3, respectively. Seven MDH isoforms were detected in the muscle tissue (MDH-1 to MDH-7). MDH-1 levels of specimens collected at P3 were 1.9 and 2.4 times higher than those from P1 and P2, respectively. However, the levels of MDH-5, -6 and -7 of $\mathrm{P} 3$ specimens were significantly lower than $\mathrm{P} 1$ ones. These results are possibly related to water quality, considering that $\mathrm{P} 3$ is the most polluted among the three sampling sites. The muscle MDH activity of $A$. bimaculatus was modulated by the environment. Therefore, it can be concluded that this enzyme could be used as a biomarker of environmental change of the hydrographic basin of a neotropical region, where this species occurs.
\end{abstract}

Keywords: enzymes, water pollution, yellow tail lambari.

\section{INTRODUÇÃO}

A bacia hidrográfica do rio Una apresenta uma extensão de $442,85 \mathrm{~km}^{2}$, sendo que $84 \%$ dessa área encontram-se no município de Taubaté. O seu rio principal, Una, é utilizado como manancial de água para abastecimento público desse município (Banco de Dados Ambientais da Bacia do Rio Una - http://www.agro.unitau.br/una). O monitoramento da qualidade da água é realizado pela Companhia Ambiental do Estado de São Paulo (CETESB) no ponto de captação para abastecimento da Companhia de Saneamento Básico do Estado de São Paulo (SABESP) (CETESB, 2009), mas um monitoramento regular em outros pontos da bacia não tem sido realizado. Apesar disso, estudos microbiológicos e ecotoxicológicos foram realizados em alguns locais da bacia e em determinados períodos. A qualidade sanitária da água superficial em oito pontos foi analisada por Silva e Ueno (2008), que verificaram nos meses chuvosos, as taxas de coliformes totais e termotolerantes elevadas, ultrapassando os valores permitidos a rios de classe 2, os quais têm as suas características definidas na resolução CONAMA 357 (2005). Segundo essas autoras, as atividades antrópicas (agropastoris e ocupação urbana) e a presença de animais nas proximidades dos rios da bacia do Una, contribuíram para o aumento dessas taxas. Alves e Cobo (2013) analisaram seis pontos da mesma bacia, entre março e outubro de 2011, por meio da utilização de um bioindicador, o microcrustácio Ceriodaphinia dubia, que foi submetido a testes de toxicidade. Foi encontrado baixo nível de toxidade aguda (taxa de sobrevivência), mas foi detectada toxidade crônica (taxa de natalidade) em alguns pontos avaliados, em determinados meses do ano. Esses estudos revelaram a necessidade de um monitoramento mais rigoroso em vários pontos da bacia, que pode ser realizado utilizando-se biomarcadores bioquímicos, pois eles podem detectar alterações biológicas subletais, úteis na identificação e avaliação dos riscos ambientais (Jemec et al., 2010).

O complexo de espécies Astynax bimaculatus (lambari do rabo amarelo) apresenta ampla distribuição neotropical, é migratório e bem adaptado para águas correntes e estagnadas, mas pouco investigado em estudos de impacto ecológico (Paiva et al., 2006). Baixas concentrações 
de zinco (3 a $5 \mathrm{mg} / \mathrm{L}$ ) aceitas pela resolução CONAMA 357 (até $5 \mathrm{mg} / \mathrm{dL}$ ), são capazes de promover danos hepáticos e comprometer a reprodução desses lambaris, mostrando que essa espécie é um potencial bioindicador de contaminação por zinco (Marques dos Santos et al., 2015). Produtos farmacêuticos e seus derivados metabólicos, especialmente hormônios esteróides, os quais estão normalmente presentes em corpos d'água contaminados por efluentes de esgoto, descartes industriais, bem como efluentes das atividades de aquicultura e pecuária (Bottoni et al., 2010), são capazes de comprometer a função hormonal de peixes e promover citotoxicidade, estrogenecidade e androgenecidade (Leusch et al., 2014). No caso do lambari A. bimaculatus, o derivado hormonal 17- $\alpha$-metiltestoterona foi capaz de reduzir a espermatogênese e potencialmente comprometer a reprodução (Rivero-Wendt et al., 2013).

Os níveis hepáticos das enzima superóxido dismutase (SOD) e catalase (CAT) de $A$. bimaculatus foram investigados quanto ao seu uso como biomarcadores de poluição em três sítios de coleta da bacia do rio Una. O aumento expressivo dos níveis de CAT em dois dos três sítios de coleta, bem como a redução dos níveis de SOD em um dos sítios de coleta, sugerem que essas duas enzimas podem ser utilizadas como biomarcadores de estresse oxidativo (Batista et al., 2014). Enzimas da defesa antioxidante de lambaris foram utilizados como biomarcadores de poluição ambiental, em estudo conduzido no bioma do Pampa. Os níveis das enzimas SOD, CAT, glutationa-S-transferase e glutationa peroxidase foram modulados por poluentes presentes nas águas de rios contaminados por efluentes urbanos e da agricultura local (CostaSilva et al., 2015). A contaminação de ambientes aquáticos por efluentes de esgoto é capaz de modular expressivamente os níveis de enzimas do metabolismo energético de algumas espécies de peixes (Rodrigues et al., 2015). Nesse sentido, o nível da enzima lactato desidrogenase (LDH) branquial de $A$. bimaculatus da bacia do rio Una, foi 3 vezes maior em sítios com baixa demanda química de oxigênio (DQO), em relação àqueles com elevada DQO (Ribeiro et al., 2015).

Malato desidrogenase (MDH, EC: 1.1.1.37) catalisa a reação reversível de oxidação de malato a oxaloacetato, reduzindo NAD a NADH. Vertebrados e invertebrados apresentam MDH citosólico (cMDH) e mitocondrial (mMDH). Ambas as formas são produzidas no citosol a partir de genes distintos, mas mMDH é posteriormente exportada para matriz mitocondrial (Basaglia, 1989; Musrati et al., 1988). A mMDH é uma enzima do ciclo de Krebs enquanto a enzima citosólica participa do sistema de lançadeira malato-aspartato, assegurando a troca de equivalentes redutores, na forma de malato/oxaloacetato, através da membrana mitocondrial. Além disso, MDH tem envolvimento na gliconeogênese e lipogênese. Na gliconeogênese, o oxaloacetato formado a partir do piruvato deve ser reduzido a malato pela mMDH. O malato é transportado ao citosol e reconvertido em oxaloacetato pela cMDH. Na lipogênese, mMDH converte malato a oxaloacetato que, por sua vez, contribui para formação de citrato mitocondrial. Este último, ao ser transportado ao citosol, origina acetil-coenzima A para a biossíntese de lipídios e o oxaloacetato, que pode ser reduzido a malato pela cMDH. O malato pode retornar à matriz mitocondrial completando o ciclo (Nelson e Cox, 2011).

Alguns autores referem-se à cMDH como MDH da fração sobrenadante (sMDH), conforme recomendação de Shaklee et al. (1990). No caso em que a mitocôndria é removida do homogeneizado celular durante o processo da extração, e a enzima é claramente de origem citosólica, ela tem sido designada como cMDH (Mishra e Shukla, 1997). No presente estudo estaremos utilizando cMDH como sinônimo de sMDH.

Em peixes, MDH é geralmente codificada em três loci gênicos, sendo que cMDH é codificada em dois "loci” localizados em cromossomos diferentes. Cada locus codifica um monômero, cuja associação de seus produtos gênicos origina os homodímeros $\mathrm{A}_{2}$ ou $\mathrm{B}_{2}$, ou o heterodímero $\mathrm{AB}$. Um único "locus" codifica $\mathrm{mMDH}$, que também forma um dímero (Basaglia, 1989). A ocorrência de 3 isozimas de cMDH foi também confirmada em 20 espécies de peixes, pertencentes às ordens Characiformes, Siluriformes e Perciformes, coletados no 
norte do estado de São Paulo e no sul de Minas Gerais (Monteiro et al., 1991). Entretanto, alguns peixes ciclídeos (ordem Perciformes) amazônicos apresentaram 6 bandas de cMDH na eletroforese, que seriam produtos de 3 loci distintos que se associaram formando dímeros (Farias e Almeida-Val, 1992). Em Astyanax fasciatus (lambari do rabo vermelho), ocorrem 3 isozimas de cMDH no músculo (De Luca et al., 1983).

As isoformas de MDH podem apresentar diferenças quanto à termoestabilidade, à cinética de inibição e à afinidade por substratos, e, tem sido proposto que essas isoenzimas apresentam diferentes papeis fisiológicos (Barcellos Schwantes e Schvwantes, 1982; Aquino-Silva et al., 2003; Mishra e Shukla, 2003). Além disso, os níveis de MDH total e das isoformas podem ser modulados pelas condições ambientais dos locais em que vivem os peixes. Nos tecidos ocular e muscular de carpas Cirrhinus mrigala e no tecido cardíaco de carpa Labeo rohita, as isozimas de MDH apresentaram padrões de migração eletroforética diferentes em relação ao local de coleta dos peixes (lagoas de águas não residuárias e residuárias) sugerindo que poluentes podem regular a expressão e/ou atividade dessas isozimas (Manna e Chakraborty, 2012). Os níveis de MDH hepática do peixe Oreochromis mossambicus, coletados em águas próximas da descarga de esgoto não tratado da cidade Nellore na Índia, foram menores do que no sítio assumido como controle, devido a sua distância de fontes poluidoras (Gupta et al., 2016). Diferentemente, Almeida-Victor e Rodrigues (2009), trabalhando com o bagre Genidens genidens, encontraram níveis significativamente mais elevados de MDH muscular em peixes coletados na região estuarina do rio Indaiá, a qual recebe efluentes de atividades humanas, do que em peixes coletados no sítio controle, distante de fontes poluidoras.

O objetivo do presente trabalho foi analisar a atividade de MDH e de suas isozimas no tecido muscular de A. bimaculatus para avaliar o seu potencial como biomarcador bioquímico de alterações ambientais na bacia hidrográfica do rio Una.

\section{MATERIAIS E MÉTODO}

\subsection{Material biológico e locais de coleta}

Os espécimes de lambaris (Astyanax bimaculatus) foram capturados com linha e anzol e/ou rede de pesca na bacia hidrográfica do rio Una, no município de Taubaté (SP), entre de novembro de 2013 e fevereiro de 2014. Os sítios de coleta foram: a) rio Itaim (P1), nas dependências da Fazenda Piloto da Universidade de Taubaté (S 2301'38,3”, W 45³0'31,6”); b) Remédios (P2), em um córrego (valeta) localizado à beira da estrada municipal de Remédios (S 2303'26,4", W 4530'23,5"); c) Ipiranga (P3), em um córrego sem nome que cruza a Estrada Municipal Dr. José Luiz Cembranelli (S 2301 '49,4”,W 45³0'16,7’). Os peixes foram imediatamente anestesiados com benzocaína $0,1 \%(\mathrm{p} / \mathrm{v})$ dissolvida na água do rio, mortos imediatamente por decapitação e dissecados. $\mathrm{O}$ tecido muscular foi armazenado a $-86{ }^{\circ} \mathrm{C}$ até o momento da utilização. A captura dos peixes foi autorizada pelo Ministério do Meio Ambiente (SISBIO, $\mathrm{n}^{\circ}$. 41097-1) e pelo Comitê de Ética da Universidade de Taubaté (CEUA/UNITAU $\mathrm{n}^{\circ}$.013/2013).

\subsection{Homogeneizados teciduais}

Amostras de músculos de 16 espécimes (4 de cada local de coleta), foram homogeneizadas em Potter-Elvehjen, utilizando tampão Tris- $\mathrm{HCl} 50 \mathrm{mM}(\mathrm{pH} 7,4)$ na proporção $1: 5$ massa $(\mathrm{g})$ /volume (mL). O homogeneizado foi sonicado durante 20 segundos (Fisher Scientific, Sonic Dismembrator 100), para romper estruturas subcelulares, e centrifugadas a $10.000 \mathrm{~g}$ (Eppendorf 5810R) durante 10 minutos. Os sobrenadantes foram utilizados para determinação da atividade de MDH e para a eletroforese. 


\subsection{Análises bioquímicas}

A atividade da MDH foi determinada em Tris-HCl $50 \mathrm{mM}(\mathrm{pH} 7,4)$, contendo oxaloacetato $0,4 \mathrm{mM}, \mathrm{MgCl}_{2} 20 \mathrm{mM}$ e NADH+H${ }^{+} 150 \mu \mathrm{M}$ (Childress e Somero, 1979). A redução da absorbância foi acompanhada em $\lambda=340 \mathrm{~nm}\left(\varepsilon=6,22 \mathrm{mM}^{-1} \mathrm{~cm}^{-1}\right)$. A temperatura foi mantida em $25{ }^{\circ} \mathrm{C}$ por sistema Peltier do espectrofotômetro Beckman DU640. A atividade da MDH foi expressa em $\mu \mathrm{mol}$ de substrato transformado em produto no tempo de 1 minuto (U). As atividades foram normalizadas em função da concentração de proteínas totais e expressas em $\mathrm{U} \mathrm{mg}{ }^{-1}$. A proteína total foi determinada pelo método de Bradford (1976), utilizando-se soroalbumina bovina (BSA) como padrão.

\subsection{Identificação de isozimas de MDH}

$\mathrm{O}$ perfil isozimático de $\mathrm{MDH}$ foi caracterizado por meio da eletroforese em gel de poliacrilamida $7 \%(\mathrm{p} / \mathrm{v})$ sob condições não desnaturantes. A eletroforese foi conduzida em tampão contendo Tris $25 \mathrm{mM}$ e Glicina $192 \mathrm{mM}$ durante 3 horas a $4{ }^{\circ} \mathrm{C}$, aplicando uma voltagem de $100 \mathrm{~V}$ (Davis, 1964). A atividade da MDH foi revelada incubando o gel de poliacrilamida em tampão Tris- $\mathrm{HCl} 168 \mathrm{mM}\left(\mathrm{pH}\right.$ 7,9), contendo L-malato $210 \mathrm{mM}, \mathrm{NAD}^{+} 300$ $\mu \mathrm{M}$, azul de nitrotetrazólio (NBT) $26 \mu \mathrm{M}$ e fenazina metassulfato (PMS) $86 \mu \mathrm{M}$. O gel foi incubado no escuro, a $37{ }^{\circ} \mathrm{C}$, por pelo menos $2 \mathrm{~h}$ (Lin e Somero, 1995). O programa GelQuant.Net, da BioChemLabSolutions.com, foi utilizado para medir a densidade óptica das regiões coradas do gel e quantificar os níveis de $\mathrm{MDH}$ no gel de poliacrilamida. (http://www.biochemlabsolutions.com/GelQuantNET.html, acesso em 08/09/2016).

Foi também realizado um experimento (controle negativo) em que o gel, após eletroforese, foi incubado com todos os reagentes, exceto o substrato malato. O resultado foi ausência completa de bandas, indicando que desidrogenases inespecíficas não contribuíram para a formação de bandas.

\subsection{Análise estatística}

Foi realizada a análise de variância ANOVA, seguida de pós-teste de Tukey, utilizando-se o programa estatístico GraphPad Prism version 5.00 for Windows (GraphPad Software, San Diego, Califórnia). As diferenças entre as médias foram consideradas significativas quando $\mathrm{p}<0,05$.

\section{RESULTADOS E DISCUSSÃO}

O nível de MDH muscular de $A$ bimaculatus do sítio $\mathrm{P} 2$ foi 1,8 e 2,5 vezes maior do que os níveis encontrados em P1 e P3, respectivamente (Figura 1).

Os níveis elevados de MDH em espécimes de P2, mostraram que esse ambiente aquático foi capaz de elevar o potencial gerador de ATP muscular de A. bimaculatus. Os níveis teciduais dessa enzima em tecidos de peixes têm sido associado ao consumo de oxigênio e à capacidade aeróbia geradora de ATP (Torres e Somero, 1988; Torres et al., 2012). Alterações naturais e antrópicas de ambientes aquáticos são capazes de alterar demandas energéticas, mobilizar substratos energéticos e induzir respostas metabólicas em sistemas fisiológicos de peixes (Portner et al., 2008; Rodrigues et al., 2011). A poluição por esgoto foi capaz de elevar os níveis de substratos energéticos no sangue e enzimas do metabolismo energético hepático dos peixes antárticos Notothenia rossii e $N$. coriiceps (Rodrigues et al., 2015). A análise físico-química da água dos pontos P1, P2 e P3 já foi publicada, bem como o mapa com a localização desses pontos (Batista et al., 2014, Ribeiro et al., 2015). Esses dados da análise físico-química indicaram que a condutividade de 198,7 $\mu \mathrm{S} / \mathrm{cm}$ do ambiente aquático de $\mathrm{P} 2$ foi 1,9 vezes maior do que em P1, e, 1,6 vezes maior do que em P3, mostrando que os peixes de P2 estavam expostos a níveis elevados de eletrólitos, de um ambiente impactado (CETESB, 2009). Assim, o aumento do potencial gerador de ATP muscular dos peixes coletados em P2, indicado pelo aumento dos 
níveis de $\mathrm{MDH}$, pode ter sido necessário para sustentar processos ativos voltados para manutenção da homeostase muscular de eletrólitos (Williams e Frausto da silva, 2000).

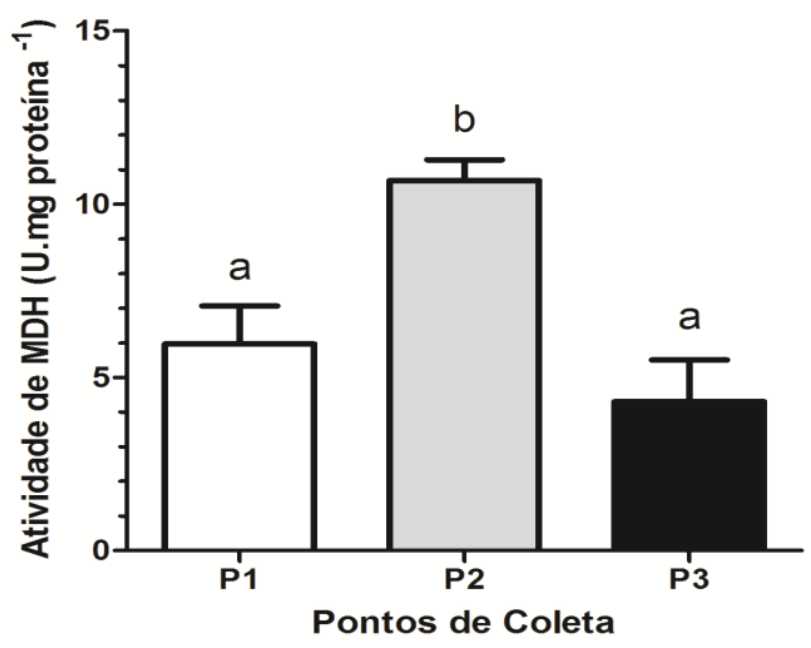

Figura 1. Níveis de MDH muscular de $A$. bimaculatus. Os valores representam a média \pm erropadrão da média. Letras diferentes acima das barras indicam diferença significativa $(p<0,05)$.

Considerando que P2 está próximo de uma área de cultivo de arroz, os níveis de MDH de A. bimaculatus podem ter sido modulados por pesticidas presentes em efluentes dessa cultura. O pesticida clorpirifós, o qual foi capaz de elevar a atividade da MDH hepática de Clarias batrachus (Narra et al., 2015), tem sido encontrado em áreas irrigadas próximas de riziculturas (Britto et al., 2015). No presente estudo, não foram quantificados os níveis de agrotóxicos na água dos três pontos de coleta. Portanto, estudos adicionais são necessários para comprovação da hipótese do envolvimento de clorpirifós sobre a elevação da atividade de MDH de $A$. bimaculatus. Outro composto que poderia elevar os níveis dessa enzima é o Benzo(a)pireno $(\mathrm{BaP})$, um Hidrocarboneto Policíclico Aromático (HPA), pois ele aumentou a expressão gênica dessa enzima no fígado do peixe Oryzias latipes (Oh et al., 2012). O BaP é considerado um dos agentes carcinogênicos, embriotóxicos e teratogênicos mais potentes com ação em animais (Caruso e Alaburda, 2008). O monitoramento da exposição ao HPA em humanos é realizado por determinação de seus metabólitos em fluidos biológicos ou dos adutos com proteínas, DNA e RNA, e mutações genéticas (aberrações cromossômicas, formação de micronúcleos, etc) (Pereira Netto et al., 2000). O monitoramento pode também ser realizado por determinação de HPA nos tecidos de peixes (Dhananjayan e Muralidharan, 2012). Entretanto, o monitoramento através dos níveis de $\mathrm{MDH}$ não tem sido relatado. Os nossos resultados sugerem que a MDH muscular de A. bimaculatus deve ser melhor investigada quanto ao seu potencial uso no biomonitoramento da presença de benzo(a)pireno e de clorpirifós nos corpos d'água da bacia hidrográfica do rio Una.

A Figura 2 mostra a distribuição de formas isozimáticas de MDH musculares de $A$. bimaculatus. Com base no padrão de migração das isozimas de Astyanax fasciatus (De Luca et al., 1983), é possível que a banda que migrou mais rapidamente para o anodo (MDH-1) seja equivalente (homólogo) ao dímero $\mathrm{B}_{2}$, sendo seguido pelos dímeros $\mathrm{AB}(\mathrm{MDH}-2)$ e $\mathrm{A}_{2}$ (MDH3). Nesse caso, esses três dímeros seriam isoformas de cMDH e as demais bandas isoformas de $\mathrm{mMDH}$, que em várias espécies, frequentemente migram mais lentamente ao anodo em relação à todas as cMDH (Thorne et al., 1963; De Luca et al., 1983; Monteiro et al., 1991). 


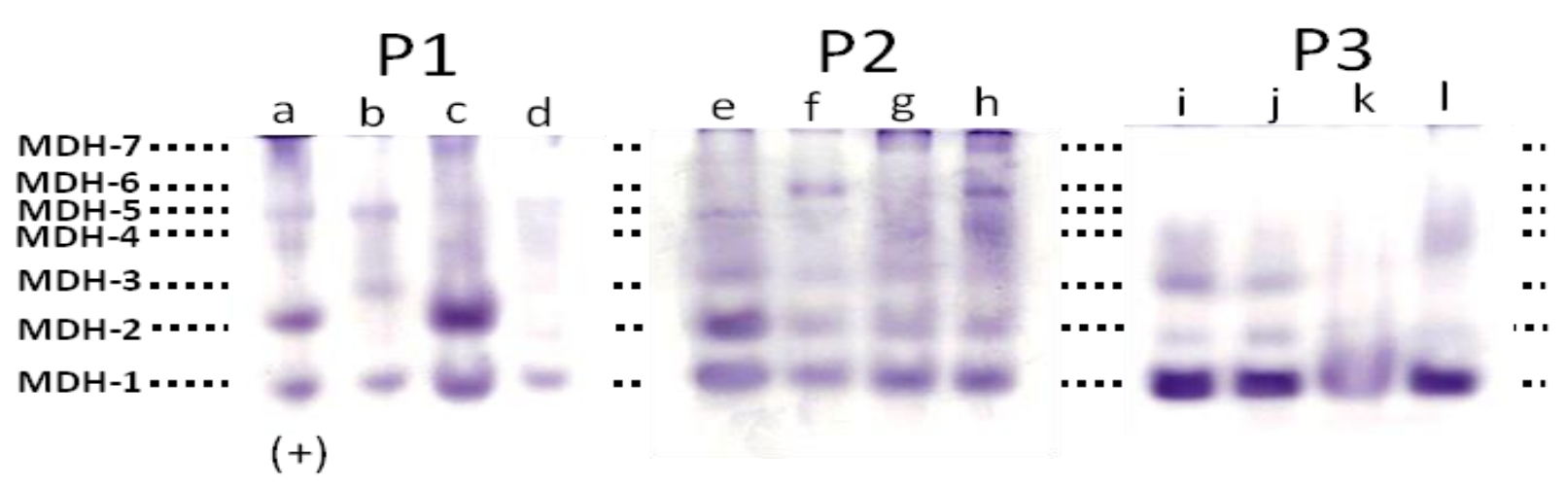

Figura 2. Atividade de isozimas de MDH extraídas do músculo de A. bimaculatus capturados em 3 locais de coleta (P1, P2 e P3). Extratos enzimáticos de cada indivíduo foram analisados (linhas a - 1). As isozimas foram separadas por eletroforese em gel de poliacrilamida, tendo sido aplicadas $15 \mu \mathrm{g}$ de proteína em cada poço.

A MDH-1 está presente em todos os indivíduos analisados (Figura 2), independentemente do local da coleta. Já as MDH-1, 2 e 3 estão presentes em todos os espécimes coletados em P2, mas não naqueles coletados em P1 e P3. Em 50\% dos espécimes de P1 (Figura 2, linhas a e c), os níveis de MDH-1 e 2 foram equitativos; e, 50\% dos espécimes de P3 (Figura 2, linhas i e j) apresentaram níveis de MDH-1, 2 e 3 com forte predominância de MDH-1. Portanto, o padrão de atividade isozimática variou entre indivíduos coletados num mesmo local. A ausência de atividade de MDH-3 (Figura 2, linhas a, k e l) sugere que o homodímero A2 não foi expresso ou não foi ativo em alguns indivíduos provenientes de P1 e P3. Mas, a subunidade A estava sendo sintetizada, pois o heterodímero AB (MDH-2) estava presente nesses indivíduos. Em um dos espécimes (Figura 2, linha b), o heterodímero AB estava ausente. Essa situação é semelhante àquela verificada em 3 espécies de peixes da ordem Siluriformes, cuja atividade do heterodímero AB não foi detectada (Monteiro et al., 1991).

Os níveis de MDH-1 muscular de espécimes coletadas em P3 foram 1,9 e 2,4 vezes maiores do que daqueles provenientes de P1 e P2, respectivamente. Por outro lado, os níveis de MDH5, -6 e -7, foram significativamente menores nos espécimes coletados em P3, em comparação com os de P1 (Tabela 1).

$\mathrm{O}$ sítio de coleta $\mathrm{P} 3$ apresenta características de um local poluído, próximo à área de pastagem e com elevada DQO, que sinaliza a presença de matéria orgânica. Em estudo anterior, realizado com o fígado desses mesmos lambaris, ficou evidente que os níveis mais elevados de catalase e superóxido dismutase, podem estar relacionados com respostas protetoras de estresse oxidativo (Batista et al., 2014). Os níveis de isozimas, convertidos em intensidades relativas da cor das bandas (Tabela 1) não foi diferente entre espécimes de P1 e P2. Entretanto, a MDH total de P1 foi menor que a de P2 (Figura.1) e deve-se à variabilidade dos níveis de MDH entre espécimes de $\mathrm{P} 1$, onde $50 \%$ apresentaram níveis relativamente baixos de $\mathrm{MDH}$ em relação ao restante dos espécimes, diferentemente dos espécimes de P2, que apresentaram níveis semelhantes MDH total (Figura 2). Portanto, de um modo geral, o padrão de isozimas variou de acordo com o ambiente em que os lambaris viviam.

O mecanismo de regulação dos níveis celulares de MDH tem sido pouco investigado em peixes. Em estudo conduzido com pré-adipócitos de camundongos (Kim et al., 2012), ficou evidente que o aumento da atividade de MDH citosólica (MDH1) decorre da acetilação da estrutura enzimática em resíduos de lisina. Nesse caso, a ativação dessa MDH1 por acetiliação, promovida por níveis citosólicos elevados de acetil-coenzima A, estariam acelerando a transferência de cadeias carbônicas da mitocôndria para o citosol e favorecendo o processo de lipogênese. Em leveduras, após um período de privação de glicose, a reintrodução desse 
monossacarídeo promove fosforilação de uma MDH citosólica (MDH2) que, nesse estado, é encaminhada à via catabólica. Consequentemente, ocorre a diminuição da atividade dessa enzima. Foi sugerido que o aumento da oferta de glicose para a levedura inibe a gliconeogênese, e, a atividade de MDH seria inibida, pois ela estaria envolvida nesse processo (Minard e McAlister-Henn, 1994; Hung et al., 2004).

Tabela 1. Intensidade relativa (\%) da coloração das bandas eletroforéticas de MDH do músculo de A. bimaculatus coletado em três locais (P1, P2 e P3).

\begin{tabular}{cccc}
\hline Isozimas & \multicolumn{3}{c}{ Pontos de Coleta } \\
\cline { 2 - 4 } & $\mathrm{P} 1$ & $\mathrm{P} 2$ & $\mathrm{P} 3$ \\
\hline MDH-1 & $27,4 \pm 6,4^{\mathrm{a}}$ & $22,1 \pm 1,3^{\mathrm{a}}$ & $52,6 \pm 3,7^{\mathrm{b}^{* * *}}$ \\
MDH-2 & $22,0 \pm 14,0^{\mathrm{a}}$ & $20,6 \pm 5,1^{\mathrm{a}}$ & $14,5 \pm 2,1^{\mathrm{a}}$ \\
MDH-3 & $10,8 \pm 7,5^{\mathrm{a}}$ & $15,0 \pm 1,0^{\mathrm{a}}$ & $12,4 \pm 5,4^{\mathrm{a}}$ \\
MDH-4 & $10,7 \pm 2,4^{\mathrm{a}}$ & $10,4 \pm 2,4^{\mathrm{a}}$ & $10,1 \pm 3,0^{\mathrm{a}}$ \\
MDH-5 & $14,7 \pm 5,5^{\mathrm{a}}$ & $10,1 \pm 2,5^{\mathrm{ab}}$ & $5,4 \pm 1,4^{\mathrm{b}^{*}}$ \\
MDH-6 & $5,3 \pm 2,1^{\mathrm{a}}$ & $11,1 \pm 5,8^{\mathrm{ab}}$ & $2,7 \pm 0,9^{\mathrm{b}^{*}}$ \\
MDH-7 & $9,2 \pm 5,1^{\mathrm{a}}$ & $10,8 \pm 2,0^{\mathrm{a}}$ & $2,3 \pm 0,5^{\mathrm{b}^{* *}}$ \\
\hline
\end{tabular}

Nota: A soma das intensidades relativas de todas as bandas de um indivíduo foi considerado $100 \%$. Os valores representam a média \pm desvio-padrão dos indivíduos provenientes de um mesmo local. Letras diferentes na mesma linha indicam diferença significativa, onde *** $p<0,0001 ; * * p<0,01 ; * p<0,05$.

Com relação à $\mathrm{mMDH}$, tem sido proposto que, em células de linhagem hipocampal de camundongo, microRNAs (miRNA) promovem a degradação do RNA mensageiro para essa enzima numa etapa pós-transcricional, contribuindo para diminuir a atividade da enzima. Entretanto, quando essas células foram submetidas a condições de estresse oxidativo, houve diminuição do nível de miRNA e houve um aumento dos níveis do RNA mensageiro para MDH. Consequentemente, houve o aumento da atividade dessa enzima (Shi e Gibson, 2011). Em outros casos, a forma mitocondrial da enzima pode também ser inibida na medida em que ocorre a dissociação do dímero em baixas concentrações da enzima e em meio ácido . Essa forma é regulada alostericamente por citrato (podendo ser ativada ou inibida, dependendo da concentração do substrato), inibida por 2-tenoiltrifluoroacetona, ATP, ADP, AMP, fumarato, aspartato e apresenta inibição pelo substrato, o oxaloacetato (Dasika et al., 2015). Portanto, a diferença nos padrões de atividade pode ser decorrente de diferentes mecanismos de regulação da enzima, desencadeada por fatores endógenos e exógenos, incluindo os contaminantes ambientais.

\section{CONCLUSÃO}

Os níveis de $\mathrm{MDH}$ muscular foram aumentados em A. bimaculatus coletados nas proximidades de uma área agrícola (P2), sugerindo a necessidade de uma investigação da contaminação por clorpirifós e/ou $\mathrm{BaP}$ na bacia hidrográfica do Una. Foram detactadas 7 isoformas de $\mathrm{MDH}$. O nível da isoforma $\mathrm{MDH}-1$ foi maior em lambaris coletados em $\mathrm{P} 3$, em comparação com os de P1 e P2. Por outro lado, os níveis de MDH-5, -6 e -7 foram menores em espécimes coletados em P3, em comparação com P1. Portanto, as atividades de isozimas de MDH muscular de A. bimaculatus são sensíveis às alterações ambientais. Assim, os níveis de MDH desse peixe podem constituir um marcador bioquímico para o biomonitoramento das águas da bacia hidrográfica do rio Una e das outras bacias, considerando que a espécie apresenta 
ampla distribuição geográfica. A abundância do tecido muscular em relação aos demais tecidos, também favorece a utilização de MDH muscular para esse propósito.

\section{AGRADECIMENTOS}

Maria Tereza Oliveira Batista recebeu bolsa de iniciação científica PIBIC/ CNPq (IBB_23_2013).

\section{REFERÊNCIAS}

ALMEIDA-VICTOR, R.; RODRIGUES, E. Resposta metabólica aeróbia, anaeróbia e argininolítica do bagre Genidens genidens, presentes nos estuários dos rios Grande, Indaiá e Escuro do município de Ubatuba. Revista Biociências, v. 15, n. 1, p. 56-54, 2009.

ALVES, T.; COBO, V. J. Bioindicador Ceriodaphnia dubia aplicado na avaliação ecotoxicológica da água da bacia hidrográfica do rio Una. Revista Ambiente \& Água, v. 8, n. 4, p. 168-182, 2013. Disponível em : http://www.scielo.br/scielo.php?script=sci_ arttext\&pid=S1980-993X2015000400793

AQUINO-SILVA, M. R.; SCHWANTES, M. L. B.; SCHWANTES, A. R. Isoform expression in the multiple soluble malate dehydrogenase of Hoplias malabaricus (Erythrinidae, Characiformes). Brazilian Journal of Biology, v. 63, p. 7-15, 2003. Disponível em: http://dx.doi.org/10.1590/S1519-69842003000100003

BARCELLOS SCHWANTES, M. L.; SCHWANTES, A. R. Adaptative features of ectothermic enzymesâ€'I. Temperature effects on the malate dehydrogenase from a temperate fish Leiostomus xanthurus. Comparative Biochemistry and Physiology Part B: Comparative Biochemistry, v. 72, n. 1, p. 49-58, 1982. http://dx.doi.org/10.1016/03050491(82)90009-8

BASAGLIA, F. Some aspects of isozymes of lactate dehydrogenase, malate dehydrogenase and glucosephosphate isomerase in fish. Comparative biochemistry and physiology. B, $\begin{array}{llllllll}\text { Comparative biochemistry, } & \text { v. } 92, \quad \text { n. } 2, \quad \text { p. } 213-226, & \end{array}$ http://dx.doi.org/10.1016/0305-0491(89)90269-1

BATISTA, M. T. O.; JUNIOR, E. R.; FEIJÓ-OLIVEIRA, M.; RIBEIRO, A. C.; RODRIGUES, E.; SUDA, C. N. K. et al. Tissue levels of the antioxidant enzymes superoxide dismutase and catalase in fish Astyanax bimaculatus from the Una River Basin. Revista Ambiente \& Agua, v. 9, n. 4, p. 621-631, 2014. http://dx.doi.org/10.4136/ambi-agua.1473

BOTTONI, P.; CAROLI, S.; CARACCIOLO, A. B. Pharmaceuticals as priority water contaminants. Toxicological and Environmental Chemistry, v. 92, n. 3, p. 549-565, 2010. http://dx.10.1080/02772241003614320

BRADFORD, M. M. A rapid and sensitive method for the quantitation of microgram quantities of protein utilizing the principle of protein-dye binding. Analytical Biochemistry, v. 72, n. 1-2, p. 248-254, 1976. 
BRITTO, F. B.; SILVA, T. M. M. D.; VASCO, A. N. D.; AGUIAR NETTO, A. O.; CARVALHO, C. M. D. Avaliação do risco de contaminação hídrica por agrotóxicos no perímetro irrigado Betume no baixo rio São Francisco. Revista Brasileira de Agricultura Irrigada, v. 9, n. 3, p. 158 - 170, 2015.

http://dx.doi.org/10.7127/rbai.v9n300301

CARUSO, M. S. F.; ALABURDA, J. Hidrocarbonetos policíclicos aromáticos benzo(a)pireno: uma revisão. Revista do Instituto Adolfo Lutz, v. 67, n. 1, p. 1-27, 2008.

COMPANHIA DE TECNOLOGIA DE SANEAMENTO AMBIENTAL (São Paulo) CETESB. Qualidade das águas interiores no estado de São Paulo. 2009. Disponível em: $\quad$ http://cetesb.sp.gov.br/aguas-interiores/wp-content/uploads/sites/32/2013/11/ variaveis.pdf . Acesso em: 12 nov. 2016.

CHILDRESS, J. J.; SOMERO, G. N. Depth-related enzymic activities in muscle, brain and heart of deep-living pelagic marine teleosts. Marine Biology, v. 52, n. 3, p. 273-283, 1979. http://dx.doi.org/10.1007/BF00398141

CONSELHO NACIONAL DO MEIO AMBIENTE (Brasil) - CONAMA. Resolução n. 357, de 17 de março de 2005. Diário Oficial [da] União, n. 53, 18 mar. 2005, p. 58-63.

COSTA-SILVA, D. G.; NUNES, M. E.; WALLAU, G. L.; MARTINS, I. K.; ZEMOLIN, A. P.; CRUZ, L. C. et al. Oxidative stress markers in fish (Astyanax sp. and Danio rerio) exposed to urban and agricultural effluents in the Brazilian Pampa biome. Environmental Science and Pollution Research International, v. 22, n. 20, p. 1552615535, Oct 2015. http://dx.doi.org/10.1007/s11356-015-4737-7

DASIKA, S. K.; VINNAKOTA, K. C.; BEARD, D. A. Determination of the catalytic mechanism for mitochondrial malate dehydrogenase. Biophysical Journal, v. 108, n. 2, p. 408-419, 2015. http://dx.doi.org/10.1016/j.bpj.2014.11.3467

DAVIS, B. J. Disc electrophoresis - II Method and application to human serum proteins. Annals of the New York Academy of Sciences, v. 121, n. 2, p. 404-427, 1964. http://dx.doi.org/10.1111/j.1749-6632.1964.tb14213.x

DE LUCA, P. H.; SCHWANTES, M. L. B.; SCHWANTES, A. R. Adaptative features of ectothermic enzymes - IV. Studies on malate dehydrogenase of Astyanax fasciatus (Characidae) from lobo reservoir (São Carlos, São Paulo, Brasil). Comparative Biochemistry and Physiology Part B: Comparative Biochemistry, v. 74, n. 2, p. 315324, 1983. http://dx.doi.org/10.1016/0305-0491(83)90019-6

DHANANJAYAN, V.; MURALIDHARAN, S. Polycyclic aromatic hydrocarbons in various species of fishes from Mumbai Harbour, India, and their dietary intake concentration to human. International Journal of Oceanography, v. 2012, p. 6, 2012. http://dx.doi.org/10.1155/2012/645178

FARIAS, I. P.; ALMEIDA-VAL, V. M. F. Malate dehydrogenase (sMDH) in Amazon cichlid fishes: evolutionary features. Comparative Biochemistry and Physiology Part B: Comparative Biochemistry, v. 103, n. 4, p. 939-943, 1992. http://dx.doi.org/10.1016/0305-0491(92)90219-H

GUPTHA, J. S.; RENUKA, M.; SUNEETHA, Y.; REDDY, M. S. Evaluation of antioxidant defence system during xenobiotic induced oxidative stress in freshwater fish Oreochromis mossambicus. International Journal of Fisheries and Aquatic Studies, v. 4, n. 1, p. 379-385, 2016. 
HUNG, G.-C.; BROWN, C. R.; WOLFE, A. B.; LIU, J.; CHIANG, H.-L. Degradation of the gluconeogenic enzymes fructose-1,6-bisphosphatase and malate dehydrogenase is mediated by distinct proteolytic pathways and signaling events. Journal of Biological $\begin{array}{lllllll}\text { Chemistry, } & \text { v. } 279, \quad \text { n. } 47, \quad \text { p. } & 49138-49150,\end{array}$ http://dx.doi.org/10.1074/jbc.M404544200

JEMEC, A.; DROBNE, D.; TIŠLER, T.; SEPČIĆ, K. Biochemical biomarkers in environmental studies - lessons learnt from enzymes catalase, glutathione S-transferase and cholinesterase in two crustacean species. Environmental Science and Pollution Research, v. 17, n. 3, p. 571-581, 2010. http://dx.doi.org/10.1007/s11356-009-0112-x

KIM, E. Y.; KIM, W. K.; KANG, H. J.; KIM, J. H.; CHUNG, S. J.; SEO, Y. S. et al. Acetylation of malate dehydrogenase 1 promotes adipogenic differentiation via activating its enzymatic activity. Journal of Lipid Research, v. 53, n. 9, p. 1864-1876, 2012. http://dx.doi.org/10.1194/jlr.M026567

LEUSCH, F. D. L.; KHAN, S. J.; GAGNON, M. M.; QUAYLE, P.; TRINH, T.; COLEMAN, $\mathrm{H}$. et al. Assessment of wastewater and recycled water quality: A comparison of lines of evidence from invitro, invivo and chemical analyses. Water Research, v. 50, p. 420-431, 2014. http://dx.doi.org/10.1016/j.watres.2013.10.056

LIN, J. J.; SOMERO, G. N. Temperature-dependent changes in expression of thermostable and thermolabile isozymes of cytosolic malate dehydrogenase in the eurythermal goby fish Gillichthys mirabilis. Physiological Zoology, v. 68, n. 1, p. 114-128, 1995. http://www.jstor.org/stable/30163921

MANNA, M.; CHAKRABORTY, P. Analysis of lactate and malate dehydrogenase enzyme profiles of selected major carps of wetland of Calcutta. Journal of Environmental Biology, v. 33, n. 4, p. 763-767, Jul 2012.

MARQUES DOS SANTOS, D. C.; CUPERTINO, M. D. C.; MATTA, S. L. P. D.; OLIVEIRA, J. A. D.; SANTOS, J. A. D. D. Histological alterations in liver and testis of Astyanax aff. bimaculatus caused by acute exposition to zinc. Revista Ceres, v. 62, n. 2, p. 133-141, 2015. http://dx.doi.org/10.1590/0034-737X201562020002

MINARD, K. I.; McALISTER-HENN, L. Glucose-induced phosphorylation of the MDH2 isozyme of malate dehydrogenase in Saccharomyces cerevisiae. Archives of Biochemistry and Biophysics, v. 315, n. 2, p. 302-309, 1994. http://dx.doi.org/10.1006/abbi.1994.1504

MISHRA, R.; SHUKLA, S. P. Impact of endosulfan on cytoplasmic and mitochondrial liver malate dehydrogenase from the freshwater catfish (Clarias batrachus). Comparative Biochemistry and Physiology Part C: Pharmacology, Toxicology and Endocrinology, v. 117, n. 1, p. 7-18, 1997. http://dx.doi.org/10.1016/S07428413(96)00197-1

MISHRA, R.; SHUKLA, S. P. Endosulfan effects on muscle malate dehydrogenase of the freshwater catfish Clarias batrachus. Ecotoxicology and Environmental Safety, v. 56, n. 3, p. 425-433, 2003. http://dx.doi.org/10.1016/S0147-6513(03)00006-X 
MONTEIRO, M. D. C.; SCHWANTES, M. L. B.; SCHWANTES, A. R. Malate dehydrogenase in subtropical fish belonging to the orders characiformes, siluriformes and perciformes I. Duplicate gene expression and polymorphism. Comparative Biochemistry and Physiology Part B: Comparative Biochemistry, v. 100, n. 2, p. 381-389, 1991. http://dx.doi.org/10.1016/0305-0491(91)90391-P

MUSRATI, R. A.; KOLlAROVA, M.; MERNIK, N.; MIKULASOVA, D. Malate dehydrogenase: distribution, function and properties. General Physiology and Biophysics, v. 17, n. 3, p. 193-210, 1998.

NARRA, M. R.; RAJENDER, K.; RUDRA REDDY, R.; RAO, J. V.; BEGUM, G. The role of vitamin $\mathrm{C}$ as antioxidant in protection of biochemical and haematological stress induced by chlorpyrifos in freshwater fish Clarias batrachus. Chemosphere, v. 132, p. 172-178, 2015. http://dx.doi.org/10.1016/j.chemosphere.2015.03.006

NELSON, D. L.; COX, M. M. Princípios de bioquímica de Lehninger. 5. ed. Porto Alegre: Artmed, 2011. $1274 \mathrm{p}$.

OH, J. H.; MOON, H.-B.; CHOE, E. S. Alterations in differentially expressed genes by exposure to a mixture of carcinogenic polycyclic aromatic hydrocarbons in the liver of Oryzias latipes. Environmental Toxicology and Pharmacology, v. 33, n. 3, p. 403-407, 2012. http://dx.doi.org/10.1016/j.etap.2012.01.007

PAIVA, S. R.; DERGAM, J. A.; MACHADO, F. V. Determining management units in southeastern Brazil: the case of Astyanax bimaculatus (Linnaeus, 1758) (Teleostei: Ostariophysi: Characidae). Hydrobiologia, v. 560, n. 1, p. 393-404, 2006. http://dx.doir.org/10.1007/s10750-005-9415-1

PEREIRA NETTO, A. D.; MOREIRA, J. C.; DIAS, A. E. X. O.; ARBILLA, G.; FERREIRA, L. F. V.; OLIVEIRA, A. S. et al. Avaliação da contaminação humana por hidrocarbonetos policíclicos aromájticos (HPAs) e seus derivados nitrados (NHPAs): uma revisão metodológica. Evaluation of human contamination with polycyclic aromatic hydrocarbons (PAHs) and their nitrated derivatives (NHPAs): a review of methodology. Química Nova, v. 23, n. 6, p. 765-773, 2000. http://dx.doi.org/10.1590/S010040422000000600010

PORTNER, H. O.; BOCK, C.; KNUST, R.; LANNIG, G.; LUCASSEN, M.; MARK, F. C. et al. Cod and climate in a latitudinal cline: Physiological analyses of climate effects in marine fishes. Climate Research, v. 37, n. 2-3, p. 253-270, 2008. http://dx.doi.org/10.3354/cr00766

RIBEIRO, A. C.; BATISTA, M. T. O.; RODRIGUES JR, E.; FEIJÓ DE OLIVEIRA, M.; VANI, G. S.; RODRIGUES, E. et al. Atividades de lactato desidrogenase e malato desidrogenase de Astyanax bimaculatus (lambari) da bacia hidrográfica do rio Una como biomarcadoras de impacto ambiental. Revista Ambiente \& Água, v. 10, n. 4, p. 793 803, 2015. http://dx.doi.org/10.4136/ambi-agua.1615

RIVERO-WENDT, C. L.; MIRANDA-VILELA, A. L.; FERREIRA, M. F.; BORGES, A. M.; GRISOLIA, C. K. Cytogenetic toxicity and gonadal effects of 17 alphamethyltestosterone in Astyanax bimaculatus (Characidae) and Oreochromis niloticus (Cichlidae). Genetics and Molecular Research, v. 12, n. 3, p. 3862-3870, 2013. http://dx.doi.org/10.4238/2013 
RODRIGUES, E., JR.; FEIJÓ-OLIVEIRA, M.; SUDA, C. N. K.; VANI, G. S.; DONATTI, L.; RODRIGUES, E. et al. Metabolic responses of the Antarctic fishes Notothenia rossii and Notothenia coriiceps to sewage pollution. Fish Physiology and Biochemistry, v. 41, n. 5, p. 1205-1220, 2015. http://dx.doi.org/10.1007/s10695-015-0080-7

RODRIGUES, E.; SUDA, C. N. K.; RODRIGUES JR, E.; DE OLIVEIRA, M. F.; DOS SANTOS CARVALHO, C.; VANI, G. S. Antarctic fish metabolic responses as potential biomarkers of environmental impact. Oecologia Australis, v. 15, n. 1, p. 124-149, 2011.

SHAKLEE, J. B.; ALLENDORF, F. W.; MORIZOT, D. C.; WHITT, G. S. Gene nomenclature for protein-coding loci in Fish. Transactions of the American Fisheries Society, v. 119, n. $1, \quad$ p. $2-15, \quad 1990$ http://dx.doi.org/10.1577/15488659(1990)119\%3C0002:GNFPLI\%3E2.3.CO;2

SHI, Q.; GIBSON, G. E. Up-regulation of the mitochondrial malate dehydrogenase by oxidative stress is mediated by miR-743a. Journal of Neurochemistry, v. 118, n. 3, p. 440-448, 2011. http://dx.doi.org/10.1111/j.1471-4159.2011.07333.x

SILVA, A. B. D. A.; UENO, M. Qualidade sanitária das águas do Rio Una, São Paulo, Brasil, no período das chuvas. Revista Biociências, v. 14, n. 1, p. 82-86, 2008.

SUNEETHA, K. Effects of endosulfan and fenvalerate on carbohydrate metabolism of the freshwater fish, Labeo rohita (Hamilton). International Journal of Pharmacy and Pharmaceutical Sciences, v. 4, n. 1, p. 262-268, 2012.

THORNE, C. J. R.; GROSSMAN, L. I.; KAPLAN, N. O. Starch-gel electrophoresis of malate dehydrogenase. Biochimica et Biophysica Acta (BBA) - Specialized Section on Enzymological Subjects, v. 73, n. 2, p. 193-203, 1963. http://dx.doi.org/10.1016/09266569(63)90152-4

TORRES, J. J.; GRIGSBY, M. D.; ELIZABETH CLARKE, M. Aerobic and anaerobic metabolism in oxygen minimum layer fishes: The role of alcohol dehydrogenase. Journal $\begin{array}{lllllll}\text { of Experimental Biology, v. 215, n. 11, p. 1905-1914, } 2012 . & \text {. }\end{array}$ http://dx.doi.org/10.1242/jeb.060236

TORRES, J. J.; SOMERO, G. N. Vertical distribution and metabolism in Antarctic mesopelagic fishes. Comparative Biochemistry and Physiology Part B: Biochemistry and Molecular Biology, v. 90, n. 3, p. 521-528, 1988. http://dx.doi.org/10.1016/03050491(88)90291-X

WILLIAMS, R. J. P.; FRAUSTO DA SILVA, J. J. R. The distribution of elements in cells. Coordination Chemistry Reviews, v. 200-202, p. 247-348, 2000. http://dx.doi.org/10.1016/S0010-8545(00)00324-6 